\section{IJ§ER}

ISSN: 2149-5939
International Journal of Social Sciences and Education Research

Online, http://dergipark.gov.tr/ijsser

Volume: 3(3), 2017

\title{
Girişimcilik ve yenilikçiliğin kalkınmadaki yeri ve yükseköğretimde giri- şimciliğe verilen önemin karşılaştırmalı analizi
}

\section{The place of entrepreneurship and innovation in economical development and com- parative analysis of the importance given to entrepreneurship in higher education}

\author{
Ayşenur Akyazi ${ }^{1} \quad$ Erhan Akyazi ${ }^{2}$
}

Received Date: 02 / 02 / $2017 \quad$ Accepted Date: 03 / 06 / 2017

\begin{abstract}
$\ddot{O} z$
Girişimciliğin temelinin yenilikler olduğu kabul edilecek olursa bunun çıkış noktasının üniversiteler olmasından daha doğal bir sonuç da görülmemektedir. Gelişmiş ülkelerin ekonomik başarıları incelendiğinde girişimciliğin kalkınmalarındaki yeri rahatlıkla görülebilmektedir. Nitekim bilişim ekonomisinin anavatanı olarak görülebilecek Amerika Birleşik Devletleri'nin günümüzde elde etmiş olduğu ekonomik başarının ardında yenilikçilik ve girişimcilik sonucu üretmiş olduğu katma değeri yüksek ürünler ve hizmetler yatmaktadır. Bu çerçevede çalışma kapsamında girişimcilik ve yenilikçiliğin kalkınmadaki önemi tartışılarak, bu kavramlara eğitim ve öğretimde ne kadar önem verildiği Türkiye'deki yüksek öğretim kurumlarının müfredatları incelenerek ve yurt dışındaki rakipleri ile karşılaştırılarak analiz edilmeye çalışılacaktır.
\end{abstract}

Anahtar sözcükler: Girişimcilik, Yenilikçilik, Yüksek Öğretim.

\begin{abstract}
If the foundation of entrepreneurship is assumed to be innovations, then there is no more natural outcome than if the starting point is the universities. When the economic successes of developed countries are examined, the place of entrepreneurship in their development can be seen easily. Indeed, behind the economic success of the United States today, which can be seen as the home of the informatics economy, lies the high value-added products and services that have been produced innovation and entrepreneurship. In this context, this study will discuss the place of entrepreneurship and innovation in development and the importance given to these concepts in education by analysing and comparing the curriculum of higher education institutions in Turkey and their rivals in other countries.
\end{abstract}

Keywords: Entrepreneurship, Innovation, Higher Education.

\section{Giriș}

Düşünen ve öğrenen bir varlık olarak insan yaratılışından günümüze kadar devam eden ve muhtemelen bundan sonra da devam edecek olan bir öğrenme süreci içerisindedir. Bu sayede bilmedikleri hakkında bilgi sahibi olarak ihtiyaçlar piramidinde yer alan ihtiyaçlarını giderme yollarını keşfetmektedir. Bununla da kalmayarak, edinmiş olduğu tecrübe ve bilgileri gelecek kuşaklara aktararak nesillerinin devamını sağlamaktadır. Kısaca eğitim olarak adlandırılabilecek bu aktarma faaliyetlerinin sistematik olarak verildiği kurumlar da eğitim ve öğretim kurumları adını almaktadır. İlk ve orta öğretimde temel bilgilerle donatılan bireyler yüksek öğretimde kendilerini meslek sahibi yapacak daha derin ve pratik bilgiler ile tanışırlar. Üniversite ismi ile genelleştirebileceğimiz yüksek öğretim kurumları tarihsel süreçte kendilerini yenileyerek,

\footnotetext{
${ }^{1}$ Asst. Prof. Dr., İstanbul Aydın University, TURKEY, aakyazi@yahoo.com

${ }^{2}$ Prof.Dr., Marmara University, TURKEY eakyazi@marmara.edu.tr
} 
Akyazı, A., Akyazı, E. (2017). The place of entrepreneurship and innovation in economical development and comparative analysis of the importance given to entrepreneurship in higher education. International Journal of Social Sciences and Education Research, 3(3), 870-881.

edinmiş oldukları pratik bilgileri hayatın her alanına uyarlama noktasına gelmiş ve bu halleri ile girişimci üniversite adı ile anılır bir üniversite sınıfının doğmasını sağlamışlardır. Amacı gerçeğin peşinden koşmak olan bilimin yuvası olan üniversitelerden filizlenen yaratıcı fikirler kamu kurumları ve özel kuruluşların destekleri ile hayat bularak yeni girişimlerin doğmasına zemin hazırlayarak, üretmiş oldukları katma değerli ürünlerle aynı zamanda da ülke ekonomisine katkı sağlamaktadırlar. Nitekim her yıl açıklanan ülkelerin gelişmişliklerini gösteren istatistikler incelendiğinde de bilime dolayısı ile araştırma ve geliştirmeye yüksek pay ayıran ülkelerin listenin üst sıralarındaki yerlerini korudukları görülmektedir. Bilişim toplumunun temelini oluşturan teknolojilerin dünyaya yayıldığı ülkelere bakıldığında, hizmet sektörünün diğer sektörlerin çok önünde olduğu görülmektedir. Aynı zamanda farklı kriterler baz alınarak hazırlanan ve her yıl yenilenen üniversitelerin sıralaması incelendiğinde de aynı ülkelerin üniversitelerinin listenin başlarındaki sıralarını diğer ülkelere kaptırmadıklarına şahit olunmaktadır. Kasıtlı bir manipülasyon yoksa rakamların dili evrenseldir ve her ülkede aynı gerçekleri söylerler. Açıklanan rakamlar özellikle gelişmekte olan ülkelere gelişmiş ülkelere erişmeleri konusunda ne yapmaları gerektiğini aslında açık açık haykırmaktadır. Bu gerçek de şüphesiz bilimin ışığında araştırmaya daha fazla pay ayırarak, yeniliğin ve dolayısı ile girişimlerin önünü açmaktır.

\section{Literatür}

Türk Dil Kurumu'nun Büyük Türkçe Sözlüğü’nde girişimcilik “Emek, sermaye ve doğayı bir araya getirerek üretim sürecinin bir üretim faktörü olarak tasarlanması, örgütlenmesi ve onun tüm riskinin üstlenilmesi." şeklinde tanımlanmaktadır. (TDK, 2017) Gayet açık olan bu girişimcilik tanımında bir araya getirmek ve riski üstlenmek şeklinde iki önemli faaliyet dikkati çekmektedir. Gerçekten de girişimcilik fikir ile başlamakla birlikte, bu fikri hayata geçirecek tüm unsurları da bir araya getirmeyi gerektirmektedir. Zira sermayeden yoksun bir girişim fikrinin hayat bulması düşünülemez. Diğer taraftan girişimcilik aynı zamanda bir risk alma faaliyetidir de. Amerika Birleşik Devletleri'nin yeni bir ekonomiye dönüşmesinde önemli paya sahip Silikon Vadisi'ni doğuran en büyük etkenin risk sermayedarları ve melek yatırımcılar olduğu düşünüldüğünde, risk almanın girişimcilik için önemi bir kez daha anlaşılmış olacaktır. Girişimcilik sözcüğünün etimolojik kökeni incelendiğinde de, üstlenmek, yüklenmek anlamlarına gelen "undertake"ten türediği görülmektedir. (Etymonline, 2017) Bu konudaki alan yazında girişimcilerin gözden kaçan firsatları yakalamak ve bu firsatları iş fikrine dönüştürme şeklinde ortak yeteneklere sahip oldukları vurgulanmaktadır. Girişimcilik ile ilgili yaklaşımlar incelendiğinde 1800'lü yılların sonunda şahsi iradesi ile eylemde bulunmak girişimcilik için yeterli görülürken, 1900'lü yılların sonundan itibaren ise girişimciliğin kalkınmadaki önemine vurgu yapan ve iş yaratma süreci olan gören yaklaşıma evrildiği gözlenmektedir. (Topkaya, 2013)

Girişimciliğin ulaşmış olduğu nokta ilk yaklaşımı kapsamak ve reddetmemekle birlikte, kalkınmamış bir ülke ekonomisinde girişimciliğin de anlamının olamayacağını özetleyecek şekilde sadece şahsi iradenin yeterli olmadığına vurguda bulunmaktadır. Girişimciliğin yıldızının parlamasında pek çok neden etkili olmakla birlikte, temel nedenlerin başında ekonomik krizler gelmektedir. 1974 petrol krizi ile başlayan kapitalist sistemin çöküşü beraberinde izlenen ekonomi politikalarının yenilenmesini zorunlu kılmış ve temeli İsviçre'de atılan neoliberal ekonomi politikaları devreye sokulmuştur. Bu politikalar bir yandan ekonomiye devlet müdahalesini reddederken, diğer yandan sermayenin serbest dolaşımının yollarını açmaktadır. Nitekim günümüzde anlaşmalarla güvence altına alınan sermaye dolaşımı sayesinde girişimciler dünyanın pek 
Akyazı, A., Akyazı, E. (2017). Girişimcilik ve yenilikçiliğin kalkınmadaki yeri ve yükseköğretimde girişimciliğe verilen önemin karşılaştırmalı analizi. International Journal of Social Sciences and Education Research, 3(3), 870-881.

çok yerinden rahatlıkla sermaye bulabilmektedir. Soğuk savaşın bitmesinin ardından 90'lı yılların sonu ile birlikte başlayan küreselleşme akımı da girişimciliğin gelişiminde önemli bir rol oynamıştır.

Ünlü yönetim bilimci Peter Drucker girişimcilik ile ilgili "Girişimcilik mistik bir durum mudur? Girişimcilik bir sihir değildir, gizem değildir. Girişimcilik bir disiplindir ve herhangi bir disiplinde olduğu gibi öğrenilebilir" ifadelerini kullanmıştır. (Bozkurt, 2011) Bu ifadelerden de anlaşılacağı gibi öğretilebilir bir disiplin olan girişimcilik pek çok üniversitenin eğitim müfredatlarında yerini almıştır. Girişimcilik ile ilgili verilen ilk eğitimler teorik bilgi ağırlıklı olmakla birlikte, zamanla bu bilginin ihtiyacı karşılayamaması sonucunda üniversite dışı kurumlar uygulamalı eğitimlerle destek sağlar hale gelmişlerdir. Girişimcilik eğitimlerinde temel amaç şüphesiz bu eğitimi alacaklara öncelikle bir girişimcilik bilinci aşılamak, ardından da bu konudaki becerileri kazandırarak ülkedeki girişimcilik kültürünün yaygınlık kazanmasına destek olmaktır. (Balaban \& Özdemir, 2008) Girişimcilik eğitiminin diğer amaçları arasında işletmelere faydalı bilgiler sunarak kapasitelerini artırmak, iş durumlarına göre eylem planları oluşturmak, girişimciliği teşvik etmek sayılabilir. (Uluköy, Demireli, \& Kahya, 2013)

Girişimcilik eğitimlerine önem verilmesi hususunda Türkiye’nin Avrupa Birliği'ne üyelik süreci önemli bir yer teşkil etmektedir. 1963 yılında imzalanan Ankara Anlaşması ile başlayan Avrupa Birliği’ne üyelik süreci, 1995 yılında Gümrük Birliği ile devam etmiş ve 1999 yılında Helsinki'de gerçekleştirilen Avrupa Birliği Devlet ve Hükümet Başkanları Zirvesi sonucunda Türkiye için hazırlanan Katılım Ortaklığ 1 Belgesi ile yeni bir döneme girmiştir. Türkiye için çizilen yol haritasında yer alan önceliklerin yerine getirilmesi için 2001 yılında dönemin hükümeti tarafından bir Ulusal Program hazırlanmış ve bu program 2003 yılında gözden geçirilmiştir. Bu çerçevede 2004 yılında yayınlanan Kobi Stratejisi ve Eylem Planı'nın İlke ve Politikalar başlığı altındaki maddelerden birisi de Girişimcilik Eğitimi ve Öğretimidir. Bu maddede açık olarak "Girişimci ruhun geliştirilmesi amacıyla eğitimin her kademesinde girişimcilik eğitimi ve öğretimine yönelik programlar geliştirilecektir” ifadesi yer almaktadır. (DPT, 2017) İlave olarak 2011yılında Yükseköğretim Kurulu (YÖK) ve Küçük ve Orta Ölçekli İşletmeleri Geliştirme ve Destekleme İdaresi Başkanlığı (KOSGEB) arasında arasında imzalanan protokole göre girişimcilik dersinin üniversitelerde tüm bölümleri kapsayacak şekilde zorunlu veya seçmeli olarak okutulması karara bağlanmıştır. (KOSGEB, 2017)

Girişimcilik eğitimi ile ilgili literatür incelendiğinde farklı sınıflandırmalara gidildiği görülmektedir. Bir sınıflandırmaya göre girişimcilik farkındalık eğitimi, işe başlama ya da iş kurma eğitimi, mevcut girişimciler için sürekli eğitim ve girişimci dinamizmine yönelik eğitim söz konusu olurken, bir başka sınıflandırmaya göre ise girişim hakkında eğitim, girişimde bulunma için eğitim ve mevcut girişim için eğitim (kurumsal eğitim) türleri ile karşılaşılmaktadır. (Uygun \& Güner, 2016) Sınıflandırmalar incelendiğinde girişimcilik eğitimlerinin çoğunun kişileri bir girişimcilik eğilimine sahip ve firsat beklediklerini kabul ettikleri gözlenmektedir.

Yükseköğretim alanında uzun yıllardır kıyasıya bir rekabet hüküm sürmektedir. Bu rekabetin kaynağı kimi zaman akademik çalışmaların fazlalığı ile ortaya çıkarken, son zamanlarda da hem başarı sıralamasında üst sıralarda yer alan öğrencileri bünyesine katmak, hem de sanayi sektöründen daha fazla yatırımı kazanmak adına üniversiteler arasında görülmektedir. Bu durum hem üniversiteleri girişimci bir yapıya sürüklemekte hem de eğitim programlarında girişimcilik konusuna yer vermeyi gerekli kılmaktadır. Üniversitelerin ödeneklerinde kısıtlamaya gidilmiş ol- 
Akyazı, A., Akyazı, E. (2017). The place of entrepreneurship and innovation in economical development and comparative analysis of the importance given to entrepreneurship in higher education. International Journal of Social Sciences and Education Research, 3(3), 870-881.

ması da onları böyle bir arayışa iten nedenler arasında sayılabilir. Bir başka ifade ile günümüzde üniversiteler birer işletmeye dönüşmüş ve kendisinden beklenen faydalar çeşitlenmiştir. Fayda bekleyen çevrelerin başında da sanayi sektörü gelmektedir. Nitelikli mezunlar ve hayata geçirilebilecek projeler bekleyen sanayi sektörü üniversiteleri girişimci üniversitelere dönüştürmüştür. Girişimci üniversitelerden beklenen kendi kaynaklarını yaratmaları, piyasa ile işbirliği yaratmaları ve sürekli rekabet içinde olmalarıdır. (Özdem \& Sarı, 2008)

Amerika Birleşik Devletlerinde yapılan bir araştırmanın sonuçlarına göre girişimcilik eğitimi alan kişilerin yeni iş kurmada üç kat daha fazla eğilime sahip olduğu, kendi işinde çalışmaya üç kat daha fazla istekli oldukları, yıllık \%27 daha fazla gelir elde ettikleri, mal varlıklarının \%62 daha fazla olduğu ve çalıştıkları işten daha fazla tatmin sağladıkları ortaya çıkmıştır. (Yelkikalan, et al., 2010) Sayılan bu sonuçlar girişimcilik eğitiminin neden bu kadar önemli olduğunu kanıtlar niteliktedir.

TÜBİTAK’ın yayınlamış olduğu Girişimci ve Yenilikçi Üniversite Endeksi Gösterge Seti’ni oluşturan beş boyut şu şekildedir: (TÜBİTAK, 2017)

- Bilimsel ve Teknolojik Araştırma Yetkinliği (ağırlık oranı \%20)

- $\quad$ Fikri mülkiyet havuzu (ağırlık oran1 \%15)

- İşbirliği ve etkileşim (ağırlık oranı \%25)

- Girişimcilik ve yenilikçilik kültürü (ağırlık oranı \%15)

- Ekonomik katkı ve ticarileşme (ağırlık oranı \%25)

En düşük ağırlık oranına sahip iki boyuttan birine sahip olan girişimcilik ve yenilikçilik kültürü boyutunu belirleyen kriterlerden birisi de lisans ve lisans üstü seviyesinde girişimcilik, teknoloji yönetimi ve inovasyon yönetimi ders sayısıdır.

\section{Araştırma}

Yükseköğretim kurumlarında girişimcilik ve yenilikçiliğe ne kadar önem verildiği, bir başka ifade ile TÜBİTAK'ın boyutlarını belirlemiş olduğu Girişimci ve Yenilikçi bir üniversite olup olmadıklarını ortaya koyabilmek adına , yine bu boyutun kriterlerinden birisi olan girişimcilik, teknoloji yönetimi ve inovasyon yönetimi ile ilgili derslere üniversitelerin müfredatlarında ne kadar yer verdikleri araştırılacaktır. Her ne kadar YÖK ve KOSGEB arasında 2011 yılında girişimcilik dersinin üniversitelerin tüm bölümlerinde seçimlik veya zorunlu bir ders olarak okutulması protokol ile karara bağlanmış olsa da, yapılan ön incelemede pratikte bu kararın üniversitelerin tüm bölümlerinde hayata geçmediği saptanmıştır. Bu noktadan yola çıkarak, yukarıda isimleri anılan girişimcilik ve inovasyon yönetimi derslerinin çoğunlukla üniversitelerin işletme bölümleri ile ilgili olduğu görüşü ile çalışma üniversitelerin adında işletme ve girişim geçen bölümleri ile sınırlı tutulmuştur.

Bu kapsamda Türkiye'de Yükseköğretim Kurulu bünyesinde faaliyet gösteren üniversitelerin işletme bölümü barındırabilecek işletme, iktisadi idari bilimler, siyasal bilgiler, sosyal ve beşeri bilimler, ticari bilimler ve yönetim bilimleri fakültelerindeki lisans programları ile sosyal bilimler enstitüleri müfredatları mercek altına alınarak içerik analizi yapılmıştır. Yurt içi üniversiteler bünyesinde elde edilen sonuçlar, her yıl uluslararası boyutta atıf, endüstri geliri, uluslararasılık, araştırma ve eğitim kriterlerine üniversite sıralaması gerçekleştiren Times Higher Educa- 
Akyazı, A., Akyazı, E. (2017). Girişimcilik ve yenilikçiliğin kalkınmadaki yeri ve yükseköğretimde girişimciliğe verilen önemin karşılaştırmalı analizi. International Journal of Social Sciences and Education Research, 3(3), 870-881.

tion (THE) kuruluşunun web sitesinde yer alan işletme alanındaki en iyi 10 üniversitenin ilgili bölümlerinin müfredatları ile karşılaştırılmıştır.

\section{Bulgular}

YÖK bünyesinde faaliyet gösteren üniversitelerin bölgelere göre dağılımları Tablo 1'de yer almaktadir.

Tablo 1. Bölgelere göre YÖK bünyesindeki üniversitelerin dağılımı

\begin{tabular}{|l|c|c|}
\hline \multicolumn{1}{|c|}{ Bölge } & İl Sayısı & Yükseköğretim Kurumu Sayısı \\
\hline Akdeniz Bölgesi & 8 & 16 \\
\hline Doğu Anadolu Bölgesi & 14 & 15 \\
\hline Ege Bölgesi & 8 & 13 \\
\hline Güneydoğu Anadolu Bölgesi & 9 & 11 \\
\hline İç Anadolu Bölgesi & 13 & 37 \\
\hline Karadeniz Bölgesi & 18 & 19 \\
\hline Marmara Bölgesi & 11 & 72 \\
\hline Toplam & $\mathbf{8 1}$ & $\mathbf{1 8 3}$ \\
\hline
\end{tabular}

Web sayfasına erişilemediğinden inceleme dışı bırakılan üniversiteler Tablo 2'de yer almaktadir.

Tablo 2. Web sayfasına erişilemediğinde inceleme dışı bırakılan üniversiteler

\begin{tabular}{|l|}
\hline Anka Teknoloji Üniversitesi \\
\hline Fenerbahçe Üniversitesi \\
\hline İskenderun Teknik Üniversitesi \\
\hline İstanbul Ayvansaray Üniversitesi \\
\hline İstanbul Kent Üniversitesi \\
\hline İzmir Bakırçay Üniversitesi \\
\hline İzmir Demokrasi Üniversitesi \\
\hline
\end{tabular}

İşletme bölümünü barındırmadıklarından inceleme dışı bırakılan üniversiteler Tablo 3 ’te yer almaktadir.

Tablo 3. İşletme bölümü barındırmadığından inceleme dışı bırakılan üniversiteler

\begin{tabular}{|l|}
\hline Acıbadem Üniversitesi \\
\hline Alanya Hamdullah Emin Paşa Üniversitesi \\
\hline Amasya Üniversitesi \\
\hline Bezm-i Alem Vakıf Üniversitesi \\
\hline Biruni Üniversitesi \\
\hline Fatih Sultan Mehmet Vakıf Üniversitesi \\
\hline İstanbul 29 Mayı Üniversitesi \\
\hline İstanbul Bilim Üniversitesi \\
\hline İstanbul Rumeli Üniversitesi \\
\hline Milli Savunma Üniversitesi \\
\hline Mimar Sinan Güzel Sanatlar Üniversitesi \\
\hline Sağlı Bilimleri Üniversitesi \\
\hline Sanko Üniversitesi \\
\hline Türkiye Uluslararası İslam Üniversitesi \\
\hline Bilim ve Teknoloji Üniversitesi \\
\hline Yüksek İhtisas Üniversitesi \\
\hline İzmir Yüksek Teknoloji Enstitüsü \\
\hline
\end{tabular}


Akyazı, A., Akyazı, E. (2017). The place of entrepreneurship and innovation in economical development and comparative analysis of the importance given to entrepreneurship in higher education. International Journal of Social Sciences and Education Research, 3(3), 870-881.

İnceleme dışı bırakılan yüksekokullar Tablo 4'te yer almaktadır.

Tablo 4. İnceleme dışı bırakılan yüksekokullar

\begin{tabular}{|l|}
\hline Ataşehir Adıgüzel Meslek Yüksekokulu \\
\hline Avrupa Meslek Yüksekokulu \\
\hline Faruk Saraç Tasarım Meslek Yüksekokulu \\
\hline İstanbul Kavram Meslek Yüksekokulu \\
\hline İstanbul Şişli Meslek Yüksekokulu \\
\hline Kapadokya Meslek Yüksekokulu \\
\hline
\end{tabular}

İncelemeye alınan 153 üniversitenin 104'ü kamu, 49'u vakıf ve özel üniversitelerden oluşmaktadır. 153 üniversiteyi kapsayan araştırma evreninde 183'ü lisans, 198'i lisansüstü olmak üzere toplam 381 programın müfredatları incelenmiştir. 183 lisans programının dağılımı Tablo 5’te yer almaktadır. 198 lisansüstü programın dağılımı Tablo 6'da yer almaktadır.

Tablo 5. incelemeye alınan lisans programlarının dağılımı

\begin{tabular}{|l|c|}
\hline \multicolumn{1}{|c|}{ Program Adı } & Program Sayısı \\
\hline Denizcilik İşletmeleri Yönetimi & 1 \\
\hline Konaklama İşletmeciliği & 1 \\
\hline Girişimmcilik & 3 \\
\hline Sivil Ulaştırma İşletmeciliği & 3 \\
\hline Uluslararası İ̧̧letmecilik & 6 \\
\hline Turizm İşletmeciliği & 9 \\
\hline İşletme & 160 \\
\hline
\end{tabular}

Tablo 6. İncelemeye alınan lisansüstü programlarının dağılımı

\begin{tabular}{|l|c|}
\hline \multicolumn{1}{|c|}{ Program Adı } & Program Sayısı \\
\hline Denizcilik İşletmeciliği ve Ekonomisi & 1 \\
\hline Turizm İşletmeciliği & 1 \\
\hline Girişşmcilik & 2 \\
\hline İşletme (Doktora) & 74 \\
\hline İşletme (Yüksek Lisans) & 120 \\
\hline
\end{tabular}

66 programın müfredatlarına ulaşılamadığından inceleme gerçekleştirilememiştir. Müfredatlarında ilgili derslere yer verilmeyen kamu ve vakıf üniversitelerinin lisans ve lisansüstü programlarına göre dağılımları Tablo 7'de yer almaktadır.

Tablo 7. Yer verilmeyen derslerin programlara göre dağ 1 lımı

\begin{tabular}{|l|c|c|c|}
\hline \multicolumn{1}{|c|}{ Program Türü } & Girişimcilik & İnovasyon Yönetimi & Teknoloji Yönetimi \\
\hline Kamu Lisans & 25 & 74 & 76 \\
\hline Kamu Yüksek Lisans & 24 & 49 & 47 \\
\hline Kamu Doktora & 21 & 32 & 33 \\
\hline Kamu Toplam & $\mathbf{7 0}$ & $\mathbf{1 5 5}$ & $\mathbf{1 5 6}$ \\
\hline Vakıf Lisans & 13 & 40 & 46 \\
\hline Vakıf Yüksek Lisans & 28 & 31 & 37 \\
\hline Vakıf Doktora & 17 & 16 & 20 \\
\hline Vakıf Toplam & $\mathbf{5 8}$ & $\mathbf{8 7}$ & $\mathbf{1 0 3}$ \\
\hline Toplam & $\mathbf{1 2 8 / 3 1 5}$ & $\mathbf{2 4 2 / 3 1 5}$ & $\mathbf{2 5 9 / 3 1 5}$ \\
\hline
\end{tabular}


Akyazı, A., Akyazı, E. (2017). Girişimcilik ve yenilikçiliğin kalkınmadaki yeri ve yükseköğretimde girişimciliğe verilen önemin karşılaştırmalı analizi. International Journal of Social Sciences and Education Research, 3(3), 870-881.

Müfredatlarında ilgili derslere en az bir kez yer veren kamu ve vakıf üniversitelerinin lisans ve lisansüstü programlarına göre dağılımları Tablo 8'de yer almaktadır.

Tablo 8. En az bir kez yer verilen derslerin programlara göre dağılımı

\begin{tabular}{|l|c|c|c|}
\hline \multicolumn{1}{|c|}{ Program Türü } & Girişimcilik & İnovasyon Yönetimi & Teknoloji Yönetimi \\
\hline Kamu Lisans & 80 & 31 & 29 \\
\hline Kamu Yüksek Lisans & 33 & 8 & 10 \\
\hline Kamu Doktora & 18 & 7 & $\mathbf{4 5}$ \\
\hline Kamu Toplam & $\mathbf{1 3 1}$ & $\mathbf{4 6}$ & 5 \\
\hline Vakıf Lisans & 38 & 11 & 4 \\
\hline Vakıf Yüksek Lisans & 13 & 10 & 2 \\
\hline Vakıf Doktora & 5 & 6 & $\mathbf{1 1}$ \\
\hline Vakıf Toplam & $\mathbf{5 6}$ & $\mathbf{2 7}$ & $\mathbf{5 6 / 3 1 5}$ \\
\hline Toplam & $\mathbf{1 8 7 / 3 1 5}$ & $\mathbf{7 3 / 3 1 5}$ & \\
\hline
\end{tabular}

İlgili derslerin müfredatta seçimlik olma durumlarına göre kamu ve vakıf üniversitelerinin lisans ve lisansüstü programlarına göre dağılımları Tablo 9'da yer almaktadır.

Tablo 9. Seçimlik olma durumlarına göre derslerin programlara göre dağılımı

\begin{tabular}{|l|c|c|c|}
\hline \multicolumn{1}{|c|}{ Program Türü } & Girişimcilik & Inovasyon Yönetimi & Teknoloji Yönetimi \\
\hline Kamu Lisans & 52 & 30 & 29 \\
\hline Kamu Yüksek Lisans & 31 & 8 & 10 \\
\hline Kamu Doktora & 17 & 7 & 6 \\
\hline Kamu Toplam & $\mathbf{1 0 0}$ & $\mathbf{4 5}$ & $\mathbf{4 5}$ \\
\hline Vakıf Lisans & 18 & 9 & 4 \\
\hline Vakıf Yüksek Lisans & 12 & 10 & 1 \\
\hline Vakıf Doktora & 5 & 5 & $\mathbf{1 0}$ \\
\hline Vakıf Toplam & $\mathbf{3 5}$ & $\mathbf{2 4}$ & $\mathbf{5 5 / 5 6}$ \\
\hline Toplam & $\mathbf{1 3 5 / 1 8 7}$ & $\mathbf{6 9 / 7 3}$ & 5 \\
\hline
\end{tabular}

İlgili derslerin müfredatta zorunlu olma durumlarına göre kamu ve vakıf üniversitelerinin lisans ve lisansüstü programlarına göre dağılımları Tablo 10 'da yer almaktadır.

Tablo 10. Zorunlu olma durumlarına göre derslerin programlara göre dağılımı

\begin{tabular}{|l|c|c|c|}
\hline \multicolumn{1}{|c|}{ Program Türü } & Girişimcilik & İnovasyon Yönetimi & Teknoloji Yönetimi \\
\hline Kamu Lisans & 28 & 1 & 0 \\
\hline Kamu Yüksek Lisans & 2 & 0 & 0 \\
\hline Kamu Doktora & 1 & 0 & 0 \\
\hline Kamu Toplam & $\mathbf{3 1}$ & $\mathbf{1}$ & 0 \\
\hline Vakıf Lisans & 20 & 2 & 0 \\
\hline Vakıf Yüksek Lisans & 1 & 0 & 1 \\
\hline Vakıf Doktora & 0 & 1 & $\mathbf{1}$ \\
\hline Vakıf Toplam & $\mathbf{2 1}$ & $\mathbf{3}$ & $\mathbf{1 / 5 6}$ \\
\hline Toplam & $\mathbf{5 2 / 1 8 7}$ & $\mathbf{4 / 7 3}$ & \\
\hline
\end{tabular}

187 Girişimcilik dersi toplamda 786, 73 İnovasyon Yönetimi dersi toplamda 227 ve 56 Teknoloji Yönetimi dersi de toplamda 173 kredi olarak programlarda yerlerini almışlardır. 
Akyazı, A., Akyazı, E. (2017). The place of entrepreneurship and innovation in economical development and comparative analysis of the importance given to entrepreneurship in higher education. International Journal of Social Sciences and Education Research, 3(3), 870-881.

Times Higher Education'ın (THE) internet sitesinde "Business\&Management" alanında yapmış olduğu dünya üniversiteleri sıralamasında ilk 10 sırayı alan üniversitelerin ülkelere göre dağılımı Tablo 11'de yer almaktadır.

Tablo 11. The business\&management kategorisi ilk 10 üniversite

\begin{tabular}{|l|l|}
\hline \multicolumn{1}{|c|}{ Üniversite Adı } & \multicolumn{1}{c|}{ Ülkesi } \\
\hline University of Oxford & İngiltere \\
\hline California Institue of Technology & Amerika Birleşik Devletleri \\
\hline University of Cambridge & İngiltere \\
\hline Massachusetts Institue of Technology & Amerika Birleşik Devletleri \\
\hline University of California Berkeley & Amerika Birleşik Devletleri \\
\hline University of Pennsylvania & Amerika Birleşik Devletleri \\
\hline University of California, Los Angeles & Amerika Birleşik Devletleri \\
\hline University College London & İngiltere \\
\hline Columbia University & Amerika Birleşik Devletleri \\
\hline John Hopkins University & Amerika Birleşik Devletleri \\
\hline
\end{tabular}

İşletme alanında yüksek lisans ve doktora programları olmasına rağmen müfredatlarında belirtilen derslere yer vermeyen üniversiteler Tablo 12 'de yer almaktadır.

Tablo 12. THE Kapsamında ilgili derslere yer vermeyen üniversiteler

\begin{tabular}{|l|}
\hline University of Cambridge \\
\hline University of California, Los Angeles \\
\hline University College London \\
\hline
\end{tabular}

7 farklı üniversitede toplam 74 lisans ve lisansüstü eğitim programında ilgili derslerin programlara göre dağılımı Tablo 13 'te yer almaktadır.

Tablo 13. THE kapsamındaki üniversitelerde derslerin programlara göre dağılımı

\begin{tabular}{|l|c|c|c|}
\hline \multicolumn{1}{|c|}{ Program Türü } & Girişimcilik & İnovasyon Yönetimi & Teknoloji Yönetimi \\
\hline İşletme-Lisans & 5 & 1 & 1 \\
\hline İşletme-Yüksek Lisans & 18 & 9 & 4 \\
\hline İşletme-Doktora & 1 & 1 & 0 \\
\hline İşletme Toplam & $\mathbf{2 4}$ & $\mathbf{1 1}$ & $\mathbf{5}$ \\
\hline Mühendislik-Lisans & 2 & 11 & 3 \\
\hline Mühendislik-Yüksek Lisans & 17 & 0 & 0 \\
\hline Mühendislik-Doktora & 0 & $\mathbf{1 1}$ & $\mathbf{4}$ \\
\hline Mühendislik Toplam & $\mathbf{1 9}$ & $\mathbf{2 2}$ & $\mathbf{9}$ \\
\hline Toplam & $\mathbf{4 3}$ & & 1 \\
\hline
\end{tabular}

4 kredilik 5, 3 kredilik 67 ders var iken, Türkiye'deki üniversitelerde rastlanılmayan laboratuar derslerinin 2 ve seminer derslerinin ise 0 kredi oldukları görülmüştür.

Yabancı üniversitelerdeki programlarda Türkiye'deki üniversitelerin programlarında rastlanılmayan girişimciliğin yasal boyutu, girişimciliğin finansmanı ve atölye gibi derslere de yer verildiği gözlenmiştir. 
Akyazı, A., Akyazı, E. (2017). Girişimcilik ve yenilikçiliğin kalkınmadaki yeri ve yükseköğretimde girişimciliğe verilen önemin karşılaştırmalı analizi. International Journal of Social Sciences and Education Research, 3(3), 870-881.

\section{Sonuç ve tartışma}

Araştırma bulguları incelendiğinde konu ile ilgili özel çıarımlardan önce üniversite tercihini yapacak milyonlarca öğrencinin programlarla ilgili bilgilere erişebileceği ortamların en başında gelen internette halen sayıları azımsanamayacak kadar çok olan programların bulunmasının üzüntü verici olduğunu bildirmek doğru olacaktır.

Alanı işletme olan programların 1/3'ünde girişimcilik ve 2/3'ünde Yenilik Yönetimi ile Teknoloji Yönetimi derslerine hiç yer verilmemiş olması bilişim teknolojileri ile iş yapmanın şimdiye kadar hiç bu kadar kolay olmadığı günümüz küresel dünyasında kelime kökünde evrensel geçen üniversitelerimize yakışmadığının da belirtilmesi gerekmektedir. İlave olarak oransal açıdan bakıldığında amacı daha fazla öğrenci çekmek olan özel ve vakıf üniversitelerinde bu derslere daha fazla oranda yer verilmemiş olması da düşündürücüdür. Ayrıca her ne kadar çogunlukla ve özellikle ülkemizde akademik kariyer yolundaki hedeflere hizmet eden lisansüstü eğitiminde yer verilmesi beklenmese de, dünyada üst sıralara yerleşmiş üniversiteler ile karşılaştırıldığında tam tersi bir durum gözlenmektedir.

Programlarda en az bir kez yer almaları açısından bakıldığında girişimcilik konusunun yenilik ve teknoloji yönetimi konusuna göre daha iyi olması, girişimciliğin üniversiteler tarafından keşfedildiğini göstermekle birlikte, ancak diğer konuların da artan öneminin farkına varılarak, üniversitelerimizin oransal olarak karşılaştırıldığında benzer durumda olan dünyadaki rakiplerinin önüne geçmeleri adına bu durumu değerlendirmeleri gerekmektedir. Bu konu özellikle gelişmekte olan ve potansiyel taşıyan ülkemiz için ayrı önem arz etmektedir.

Seçimlik ve zorunlu olma durumları açısından incelendiğinde ise, az da olsa programlarda yer bulmuş söz konusu derslerin büyük bir oranının zorunlu olması beklendiği halde seçimlik olarak sunulmuş olması da ayrı bir düşündürücü konudur. Özgür düşünce ortamında öğrencilerin akademik gelişimlerine yön vermelerine olanak tanıması açısından seçimlik dersler önem arz etmekle birlikte, genç işsizliğinin yüksek seyrettiği ülkemizde gençleri kendi işlerinin sahibi yapacak bu tarz dersleri daha fazla oranda zorunlu olarak sunulması beklenebilir.

Derslerin programlardaki kredileri açısından incelendiğinde dünyadaki rakipleri ile karşılaştırıldığında 3 kredi ortalamasını yakaladıklarını görmekteyiz. Girişimcilik dersi özelinde incelendiğinde ise ortalamanın 4'ün üzerinde çıkması sevinidiricidir. Bu söz konusu derse üniversitelerin daha fazla önem verdiğinin göstergesidir.

İşletme konusu ile ilgili yurt dışındaki başarılı üniversiteler incelendiğinde ilk sıralarda İngiltere ve Amerika Birleşik Devletleri kökenli üniversitelerin yer alması şaşırtıcı değildir. Zira ülkelerden biri sanayi toplumunun lideri iken, diğeri özellikle son yüzyıla yeniliğin kaynağı ülke olarak damgasını vurmuştur.

Yurtdışındaki üniversiteler incelendiğinde dikkat çekici olarak söz konusu derslere çoğunlukla lisansüstü eğitiminde özellikle yüksek lisans düzeyinde yer verdikleri görülmektedir. İlave olarak bu derslerin arasında öğrencileri daha fazla motive edecek laboratuar ve atölye tarzı derslere yer vermeleri de ülkemizdeki üniversiteler açısından dikkate alınması gereken bir noktadır.

Sonuç olarak son zamanların popüler konuları olan girişimcilik, yenilik yönetimi ve teknoloji yönetimi ile ilgili olarak yolun başında olmamıza ve alınacak çok yol olmasına rağmen kötü bir konumda olmadığımız söylenebilir. 
Akyazı, A., Akyazı, E. (2017). The place of entrepreneurship and innovation in economical development and comparative analysis of the importance given to entrepreneurship in higher education. International Journal of Social Sciences and Education Research, 3(3), 870-881.

Ülkemizdeki üniversite sayısının özellikle son dönemde hızla artış göstererek ulaşmış olduğu nokta, bu üniversitelerin bünyesinde yüzlerce program barındırması çalışmanın konu ile en ilgili olan işletme programları ile sınırlandırılması sonucunu doğurmuştur. Ancak incelenen dersler pek çok alanı ilgilendirebilecek tarzda dersler olduğundan, bundan sonraki çalışmalarda diğer branşları içeren daha kapsamlı bir araştırmanın yapılması ülkemizin kalkınması açısından çok fazla önem taşıyan konuya üniversite boyutunda daha derinlemesine bir bakış açısı getirilmesine katkı sağlayacağı düşünülmektedir.

\section{Kaynakça}

Özdem, G., \& Sarı, E. (2008). Yükseköğretimde Yeni Bakış Açılarıyla Birlikte Yeni Kurulan Üniversitelerden Beklenen İşlevler (Giresun Üniversitesi Örneği). Bilim, Eğitim ve Düşünce Dergisi , 8 (1), 4.

Balaban, Ö., \& Özdemir, Y. (2008). Girişimcilik Eğitiminin Girişimcilik Eğilimi Üzerindeki Etkisi: Sakarya Üniversitesi İIBF Örneği. Girişimcilik ve Kalkınma Dergisi , 3 (2), 137.

Bozkurt, Ö. Ç. (2011). Dünyada ve Türkiye'de Girişimcilik Eğitimi: Başarılı Girişimcilier ve Öğretim Üyelerinden Öneriler. Ankara: Detay.

DPT (28/03/2017) www3.kalkınma.gov.tr/DocObjects/Download/1159/kobistratejesi.pdf

Etymonline.

http://www.etymonline.com/index.php?allowed_in_frame $=0 \&$ search=entrepreneurship

KOSGEB (28/03/2017) http://management.kosgeb.gov.tr/Pages/UI/Haberler.aspx?ref=230

TDK

$(28 / 03 / 2017)$.

http://www.tdk.gov.tr/index.php?option=com_bts\&arama=kelime\&guid=TDK.GTS.58db6da7c7ee37. 52626541

TÜBİTAK (28/03/2017) http://www.tubitak.gov.tr/sites/default/files/gyue_gosterge_seti.pdf

Topkaya, Ö. (2013). Tarihsel Süreçte Girişimcilik Teorisi: Girişimciliğin Ekonomik Büyüme ve İstihdam Boyutu. Girişimcilik ve Kalkınma Dergisi , 8 (1), 29-51.

Uluköy, M., Demireli, C., \& Kahya, V. (2013). KOSGEB Girişimcilik Eğitimi Kurslarına Katılan Katılımcıların Girişimcilik Profiline Yönelik Bir Alan Araştırması. Girişimcilik ve Kalkınma Dergisi , 8 (2), 86 .

Uygun, M., \& Güner, E. (2016). Girişimcilik Eğiliminin Gelişiminde Girişimcilik Eğitiminin Rolü. Manas Sosyal Araştırmalar Dergisi , 5 (5), 43-44.

Yelkikalan, N., Akatay, A., Yıldırım, H. M., Karadeniz, Y., Köse, C., Koncagül, Ö., et al. (2010). Dünya ve Türkiye Üniversitelerinde Girişimcilik Eğitimi: Karşılaştırmalı Bir Analiz. KMÜ Sosyal ve Ekonomik Araştırmalar Dergisi , 12 (19), 53-54.

YÖK (28/03/2017). http://www.yok.gov.tr/web/guest/universitelerimiz 
Akyazı, A., Akyazı, E. (2017). Girişimcilik ve yenilikçiliğin kalkınmadaki yeri ve yükseköğretimde girişimciliğe verilen önemin karşılaştırmalı analizi. International Journal of Social Sciences and Education Research, 3(3), 870-881.

\section{Extended Abstract in English}

Purpose and Significance: As a thinking and learning entity, human beings are in a learning process since its creation to the present day and this process will possibly continue in the future.Thanks to this, they are discovering ways to overcome their needs in the pyramid of needs by acquiring knowledge of what they do not know. Not settling with that, they also provide the continuation of generations by transferring the experience and knowledge they have acquired to future generations. These transfer activities, which can briefly be called "education", are systematically provided by institutions that are called education and training institutions. Individuals equipped with basic knowledge in primary and secondary education acquaint themselves with deeper and more practical knowledge in higher education, which will give them professions. Higher education institutions that we can generalize with the name "university", have renewed themselves in the historical process and have come to the point of adapting the practical knowledge they have acquired to every area of life and in this way they have given rise to a university class called entrepreneurial university. The creative ideas sprouting from the universities, which are the nest of science that pursues the aim of truth, contribute to the economy of the country with the added value products they produce by laying the foundation for the birth of new enterprises with the support of public institutions and private institutions. As a matter of fact, when the statistics showing the developments of the countries announced every year are examined, it is seen that the countries which give the highest allocation to research and development keep their place in the top of the list. This fact undoubtedly opens the way for innovations and therefore initiatives by increasing the allocation. In this framework, this study will discuss the importance of innovation and entrepreneurship in development, and analyse the importance given to these concepts in education and training by examining the curricula of higher education institutions in Turkey and comparing them with their foreign competitors.

Literature: Entrepreneurship, together with an idea to start with, requires this idea to be put together with all the elements that will bring it to life. It is emphasized in the literature on this subject that entrepreneurs have the common skills of catching overlooked opportunities and transforming these opportunities into business ideas. Entrepreneurship is a discipline and can be learned as in any discipline. As it is understood from these statements, entrepreneurship, a discipline that can be taught, has taken its place in the curricula of many universities. The main purpose of entrepreneurship training is undoubtedly to raise an entrepreneurial awareness among those who will be educated and then to equip them with the necessary skills and to help spread the entrepreneurship culture within the country. In the field of higher education there has been a fierce competition for many years. This situation not only drags the universities into an entrepreneurial structure but also requires them to give place to entrepreneurship in educational programs. In other words, nowadays, universities have turned into businesses and the benefits expected from them are diversified. The industrial sector is at the forefront waiting for benefits. The industrial sector, waiting for qualified graduates and projects that can be brought to life, have transformed universities into entrepreneur universities. What is expected from entrepreneurial universities is for them to create their own resources, co-operate with the market and be in constant competition.

Methodology: The importance given to entrepreneurship and innovation in higher education institutions will be examined in terms of how much place courses related to entrepreneurship, technology management and innovation management take in the curriculum of the universities. 
Akyazı, A., Akyazı, E. (2017). The place of entrepreneurship and innovation in economical development and comparative analysis of the importance given to entrepreneurship in higher education. International Journal of Social Sciences and Education Research, 3(3), 870-881.

In this context, content analysis was carried out by examining the curricula of undergraduate programs of business administration, economic administrative science, political science, social sciences, humanities, commercial sciences and management sciences faculties and social sciences institutes of the universities operating in the Higher Education Council in Turkey, which may accommodate business programs. The results obtained within the domestic universities are compared with the curricula of the relevant departments of the top 10 universities in the business and engineering fields on the website of the Times Higher Education Foundation, which conducts university rankings on international level, in terms of industrial income, internationality, research and education every year.

Results and Conclusion: There are 183 universities in 81 provinces of Turkey that provide faculty-level education operating within the Higher Education Council. Of the 153 universities surveyed, 104 are public, 49 are foundation and private universities. In the area sample covering 153 universities, the curricula of 381 programs have been examined, of which 183 are undergraduate and 198 are graduate programs. Curricula of 66 programs could not be reached and have not been examined. Entrepreneurship course was not included in 128 programs. 242 programs did not include Innovation Management course. Technology Management course was not included in 259 programs. Entrepreneurship course took place at least once in 187 programs. Innovation Management course took place at least once in 73 programs. Technology Management course took place at least once in 56 programs. Of the 187 entrepreneurship courses, 135 were elective courses and 52 were compulsory courses. Of the 73 Innovation Management courses, 69 were elective courses and 4 were compulsory courses. Of the 56 Technology Management courses, 53 were elective courses and 3 were compulsory courses. When examining the universities abroad, it is noteworthy that these courses are mostly placed in post graduate education especially at the graduate level. In addition, it is necessary for the universities in our country to take into account that these courses include more laboratory and workshop-style courses in order to motivate students. As a result, we can say that, although we are at the start of a long road, we are not in a bad position with entrepreneurship, innovation and technology management, which have been popular in recent times. The fact that the number of universities in our country has been increasing rapidly in the recent years and that each of these universities host hundreds of programs has resulted in this study to be restricted to the business programs most relevant to the subject. 